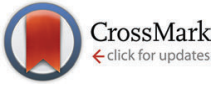

Cite this: J. Mater. Chem. C, 2015, 3, 12032

Received 30th September 2015 Accepted 26th October 2015

DOI: $10.1039 / c 5 t c 03134 f$

www.rsc.org/MaterialsC

\section{Combined experimental-theoretical study of the optoelectronic properties of non-stoichiometric pyrochlore bismuth titanate $\dagger$}

\author{
Dalal Noureldine, Sheikha Lardhi, Ahmed Ziani, Moussab Harb, * Luigi Cavallo and \\ Kazuhiro Takanabe*
}

\begin{abstract}
A combination of experimental and computational methods was applied to investigate the crystal structure and optoelectronic properties of the non-stoichiometric pyrochlore $\mathrm{Bi}_{2-x} \mathrm{Ti}_{2} \mathrm{O}_{7-1.5 x}$. The detailed experimental protocol for both powder and thin-film material synthesis revealed that a non-stoichiometric $\mathrm{Bi}_{2-x} \mathrm{Ti}_{2} \mathrm{O}_{7-1.5 x}$ structure with an $x$ value of $\sim 0.25$ is the primary product, consistent with the thermodynamic stability of the defect-containing structure computed using density functional theory (DFT). The approach of density functional perturbation theory (DFPT) was used along with the standard GGA PBE functional and the screened Coulomb hybrid HSEO6 functional, including spin-orbit coupling, to investigate the electronic structure, the effective electron and hole masses, the dielectric constant, and the absorption coefficient. The calculated values for these properties are in excellent agreement with the measured values, corroborating the overall analysis. This study indicates potential applications of bismuth titanate as a wide-bandgap material, e.g., as a substitute for $\mathrm{TiO}_{2}$ in dyesensitized solar cells and UV-light-driven photocatalysis.
\end{abstract}

\section{Introduction}

Semiconductors lie at the heart of optoelectronic technology, functioning as photon absorbers and/or as charge-carrier transporters. $\mathrm{TiO}_{2}$ is one of the most popular semiconductors for this purpose; it has been utilized in dye-sensitized solar cells ${ }^{1}$ and in basic studies of photoelectrochemical water splitting reactions. ${ }^{2}$ To improve the performance of $\mathrm{TiO}_{2}$-based devices, alternative semiconductor materials with highly effective photophysical properties, such as light absorption, charge-carrier extraction and carrier diffusion, are currently screened. Among the most promising materials are bismuth titanates, since they demonstrate great potential because of their excellent photophysical properties and their bandgaps, which can be tuned through site substitution with different elements. ${ }^{3}$ In particular, the bismuth titanate pyrochlore structure has been used as a pigment ${ }^{4}$ and, recently, as a UV-light-responsive photocatalyst. ${ }^{5-10}$

In the literature, the properties and functions of bismuth titanates remain controversial because of a lack of detailed information on their optoelectronic properties. In part, this

Division of Physical Sciences and Engineering, KAUST Catalysis Center (KCC), King Abdullah University of Science and Technology (KAUST), 4700 KAUST,

Thuwal, 23955-6900, Saudi Arabia. E-mail: moussab.harb@kaust.edu.sa, kazuhiro.takanabe@kaust.edu.sa

$\dagger$ Electronic supplementary information (ESI) available: Supplementary data for absorption and electrochemistry are presented. See DOI: 10.1039/c5tc03134f lack of clarity results from the difficulty in controlling their chemical stoichiometry through material synthesis. Pyrochlore bismuth titanate has been synthesized using several methods, including metal-organic decomposition, ${ }^{11}$ the sol-gel method, ${ }^{12}$ and co-precipitation. ${ }^{13,14}$ It was first introduced as $\mathrm{Y}_{1-x} \mathrm{Bi}_{x} \mathrm{Ti}_{2} \mathrm{O}_{7}$, and several non-stoichiometric forms have also been reported, such as the $\mathrm{Bi}^{3+}$ - and $\mathrm{O}^{2-}$-deficient compound $\mathrm{Bi}_{1.833} \mathrm{Ti}_{2} \mathrm{O}_{6.75}{ }^{15}$ Often, the perovskite $\mathrm{Bi}_{4} \mathrm{Ti}_{3} \mathrm{O}_{12}$ structure is co-generated in the attempt to synthesize the stoichiometric pyrochlore $\mathrm{Bi}_{2} \mathrm{Ti}_{2} \mathrm{O}_{7}$ through solid-state reactions. ${ }^{16}$ Later, $\mathrm{Bi}_{1.74} \mathrm{Ti}_{2} \mathrm{O}_{6.62}$ synthesized via co-precipitation was reported as a single pure product refined via neutron diffraction, thereby confirming the stoichiometry. ${ }^{17}$ Recently, a non-stoichiometric structure synthesized via an aqueous sol-gel method was reported, namely, a nonstoichiometric $\left(\mathrm{Bi}_{2-x} \mathrm{Ti}_{0.75 x}\right) \mathrm{Ti}_{2} \mathrm{O}_{7}$ material with $x$ equal to $0.44 .^{7}$ There remains a need for a detailed study to elucidate the crystal structure as well as the optical and transport properties of this non-stoichiometric $\mathrm{Bi}_{2-x} \mathrm{Ti}_{2} \mathrm{O}_{7-1.5 x}$ material.

To resolve the inconsistencies regarding the crystal structure and optoelectronic properties of pyrochlore bismuth titanate in the literature, we report here a detailed study combining both experimental and theoretical methods. On the experimental side, care was taken to synthesize the non-stoichiometric phase without any secondary phases. Density functional theory (DFT) and density functional perturbation theory (DFPT) employing both the standard Perdew-Burke-Ernzerhof (PBE) functional 
and the more accurate screened Coulomb hybrid Heyd-ScuseriaErnzerhof (HSE06) functional were employed, ${ }^{18,19}$ with the inclusion of spin-orbit coupling. Our approach enabled the determination of the electronic structure, optical absorption coefficient, dielectric constant and effective charge-carrier masses of the non-stoichiometric $\mathrm{Bi}_{1.75} \mathrm{Ti}_{2} \mathrm{O}_{6.62}$. There was good agreement between the measured and the calculated values. The impact of the non-stoichiometric structure relative to the ideal $\mathrm{Bi}_{2} \mathrm{Ti}_{2} \mathrm{O}_{7}$ stoichiometric structure on these properties was also investigated, and a general comparison of the properties with those of the well-studied material $\mathrm{TiO}_{2}$ was performed.

\section{Experimental and theoretical methods}

\section{Chemicals}

The following chemicals were used: bismuth nitrate pentahydrate (Aldrich, 99.999\%), titanium isopropoxide (Aldrich, 99.999\%), glacial acetic acid (Fisher Scientific, 99.8\%), ammonium hydroxide (Fisher Scientific, 29.44\%), methoxy ethanol (Sigma, 99\%), acetyl acetone (Aldrich, 99\%), and sodium hydroxide (Sigma-Aldrich, 99.99\%).

\section{Synthesis of bismuth titanate powders and films}

Bismuth titanate powders were synthesized using the coprecipitation method. ${ }^{14} \mathrm{Bi}\left(\mathrm{NO}_{3}\right)_{3} \cdot 5 \mathrm{H}_{2} \mathrm{O}(10 \mathrm{mmol})$ was dissolved in $25 \mathrm{ml}$ of glacial acetic acid under stirring at room temperature for $3 \mathrm{~h}$ until the solution became clear. Then, titanium isopropoxide was added to adjust the starting Ti/Bi molar ratio to values of $1,1.23,1.50,1.75$ and 2 to form crystalline samples with different stoichiometries. After $5 \mathrm{~min}$ of stirring, $33 \mathrm{ml}$ of cold ammonium hydroxide was slowly added. When the $\mathrm{pH}$ became $\sim 7$, a white precipitate was formed, which was filtered and washed extensively with Milli-Q water (>18 M $\Omega$ ). After drying at $90{ }^{\circ} \mathrm{C}$ for $24 \mathrm{~h}$, the obtained mixture was ground and heat treated at $550{ }^{\circ} \mathrm{C}$ for $16 \mathrm{~h}$ in a static furnace.

Pyrochlore bismuth titanate films were deposited using the chemical solution deposition method via the spin-coating technique. The starting solution was prepared by dissolving $3 \mathrm{mmol}$ of $\mathrm{Bi}\left(\mathrm{NO}_{3}\right)_{3} \cdot 5 \mathrm{H}_{2} \mathrm{O}$ in $5 \mathrm{ml}$ of glacial acetic acid. Methoxy ethanol $(2.5 \mathrm{ml})$ was added to adjust the tension of the solution. Then, a stoichiometric amount of titanium isopropoxide $(3.7 \mathrm{mmol}, \mathrm{Ti} / \mathrm{Bi}$ molar ratio $=1.23)$ was added, causing the solution to turn light yellow. Acetyl acetone $(1.5 \mathrm{ml})$ was added to prevent titanium complexation. In each cycle, the solution was spin coated onto a Si wafer or a fluorine-doped tin oxide (FTO) substrate at $3000 \mathrm{rpm}$ for $30 \mathrm{~s}$. Unless otherwise stated, the deposition was repeated over 10 cycles. Then, the film was dried for $5 \mathrm{~min}$ at $200{ }^{\circ} \mathrm{C}$. Finally, it was calcined at $600{ }^{\circ} \mathrm{C}$ for $2 \mathrm{~h}$.

\section{Structural and optical characterization}

$\mathrm{X}$-ray diffraction (XRD) patterns were collected using a Bruker D8 Advanced A25 diffractometer equipped with a $\mathrm{Cu}$ X-ray tube $\left(\mathrm{Cu}-\mathrm{K}_{\alpha} ; \lambda=0.15418 \mathrm{~nm}\right)$ operated at $40 \mathrm{kV}$ and $40 \mathrm{~mA}$ in the Bragg-Brentano geometry using a linear position-sensitive detector with an opening of $2.9^{\circ}$. The diffractometer was configured with a $0.44^{\circ}$ divergence slit, a $2.9^{\circ}$ anti-scatter slit, $2.5^{\circ}$ Soller slits, and a nickel filter to attenuate contributions from $\mathrm{Cu}-\mathrm{K}_{\beta}$ fluorescence. The XRD data were analyzed via the Rietveld method using the fundamental parameters approach, as implemented in the software TOPAS V4.2 (Bruker-AXS). The XRD pattern of pyrochlore bismuth titanate was refined using the cubic structure (space group $F d 3 m$ ) taken from card 01-089-4732 in the ICSD database. The profile parameters included the scale factor, a sample displacement parameter, and a three-term polynomial for the background. The fundamental parameters approach involves analytically calculating the instrumental broadening in the peak profile. The particle size was calculated from the Lorentzian contribution to this profile. The values of $R_{\mathrm{wp}}, R_{\mathrm{Bragg}}$, and the goodness of fit (GOF) were approximately 9, 3, and 2, respectively, for all refinements.

Inductively coupled plasma (ICP) measurements were performed using an Agilent 720 Series ICP-OES instrument (Agilent Technologies). Digestion of the material was performed in an ETHOS 1 microwave digestion system (Milestone $\mathrm{Srl}$ ).

The thicknesses and complex refractive indexes $(n+i k)$ of the films were determined by applying the spectroscopic ellipsometry technique to films deposited on Si substrates. Measurements were made via scanning in the 1-6 eV range using a Jobin-Yvon ellipsometer (UVISEL).

\section{Electrochemical measurements}

Electrochemical measurements were performed using Milli-Q water. Sodium hydroxide was used as received to prepare the required $0.1 \mathrm{M}$ electrolyte with $\mathrm{pH}$ 13.2. All experiments were performed using a research-grade multi-channel potentiostat (VMP3, BioLogic Science Instruments). Cyclic voltammetry (CV) experiments were performed using a regular one-compartment electrochemical cell with a three-electrode configuration. A Pt wire and an $\mathrm{Ag} / \mathrm{AgCl}$ (saturated $\mathrm{KCl}$ ) electrode were used as counter and reference electrodes, respectively. All experiments were recorded against this reference electrode, which was reported on the reversible hydrogen electrode (RHE) scale. Pyrochlore bismuth titanate films on FTO were used as the working electrodes. The $\mathrm{CV}$ results were recorded at a scan rate of $10 \mathrm{mV} \mathrm{s}^{-1}$. Electrochemical impedance spectroscopy was performed to estimate the flatband potential of the prepared samples. Prior to impedance spectroscopy, CV was conducted under Ar bubbling at a $10 \mathrm{mV} \mathrm{s}^{-1}$ scan rate from a potential of 0 to $1.7 \mathrm{~V} v s$. RHE to determine the potential window for Mott-Schottky analysis. For this analysis, we chose a potential range of $0.5-1 \mathrm{~V} v s$. RHE, in which the faradic current remains negligible. Impedance spectra were recorded between $10 \mathrm{~Hz}$ and $200 \mathrm{kHz}$, and the amplitude of the superimposed sinusoidal potential signal was $5 \mathrm{mV}$ for each of the 70 steps.

\section{Computational methods}

Starting from the cubic crystal structure of $\mathrm{Bi}_{2} \mathrm{Ti}_{2} \mathrm{O}_{7}$ (pyrochlore phase; space group is $\mathrm{Fd} 3 \mathrm{~m}$ ), which contains 16 functional units $\left(\mathrm{Bi}_{16} \mathrm{Ti}_{16} \mathrm{O}_{56}\right)$ or 88 atoms (see Fig. 1a), we modeled the nonstoichiometric $\mathrm{Bi}_{1.75} \mathrm{Ti}_{2} \mathrm{O}_{6.62}$ structures by removing two neutral $\mathrm{Bi}$ atoms and three neutral $\mathrm{O}$ atoms from various possible sites in 
(a)

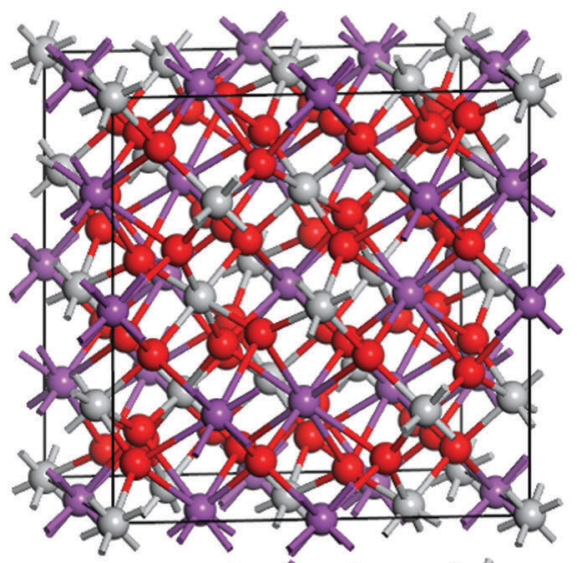

(b)

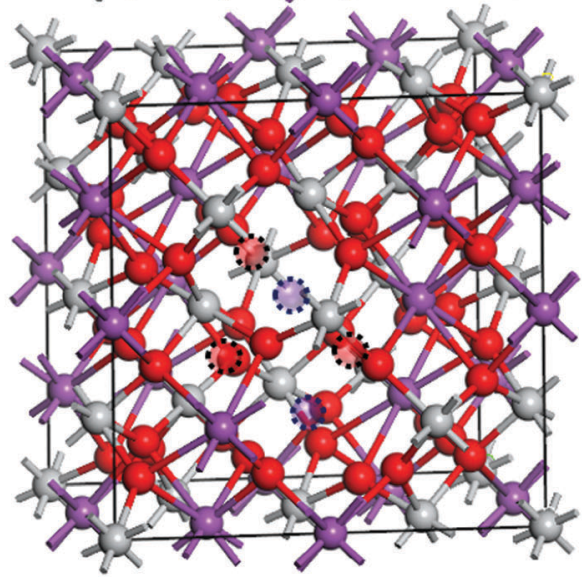

Fig. 1 DFT-optimized lowest-energy structures obtained using the PBE functional for (a) perfect $\mathrm{Bi}_{2} \mathrm{Ti}_{2} \mathrm{O}_{7}$ and (b) defect-containing $\mathrm{Bi}_{1.75} \mathrm{Ti}_{2} \mathrm{O}_{6.62}$ material with aggregated $\mathrm{Bi}$ and $\mathrm{O}$ vacancies. Color legend: $\mathrm{Bi}$ in purple, $\mathrm{Ti}$ in gray, $\mathrm{O}$ in red, and $\mathrm{Bi}(\mathrm{O})$ vacancies in dotted circles.

the cell to obtain $\mathrm{Bi}_{1.75} \mathrm{Ti}_{2} \mathrm{O}_{6.625}$. We explored several geometrical configurations by paying particular attention to key structures exhibiting separated or aggregated $\mathrm{Bi}$ and $\mathrm{O}$ vacancies (see Fig. $1 \mathrm{~b}$ and Fig. S1, ESI $\dagger$ ). In the structural models considered in our calculations, the oxidation states of the examined elements were $\mathrm{Bi}^{3+}, \mathrm{Ti}^{4+}$, and $\mathrm{O}^{2-}$. The various generated structures were optimized using periodic DFT, as implemented in $\operatorname{VASP}^{20-23}$ using the PBE exchange-correlation functional ${ }^{24}$ and the projectedaugmented plane wave (PAW) approach. ${ }^{25}$ The configurations of the valence electrons adopted in the PAW potentials were $6 \mathrm{~s}^{2} 6 \mathrm{p}^{3}$ for $\mathrm{Bi}, 3 \mathrm{~d}^{3} 4 \mathrm{~s}^{1}$ for Ti, and $2 \mathrm{~s}^{2} 2 \mathrm{p}^{4}$ for O. Cutoff energies of 500 and $610 \mathrm{eV}$ were used for the wave functions and charge augmentations, respectively. The convergence criterion for the SCF cycles was set to $10^{-5} \mathrm{eV}$ per cell. The atomic coordinates and cell parameters were fully relaxed until all components of the residual forces reached values below $0.01 \mathrm{eV} \AA^{-1}$. In all cases, the Brillouin zone was sampled using a $5 \times 5 \times$ 5 Monkhorst-Pack $k$-point grid. ${ }^{26}$

For density-of-states (DOS) calculations, we employed the screened Coulomb hybrid HSE06 exchange-correlation functional, ${ }^{27-29}$ as implemented in VASP,${ }^{20-23}$ based on the optimized geometries obtained at the PBE level. We used the tetrahedron method with Blöchl corrections for the Brillouin-zone integration.
As reported in ref. 30-32, the well-known limitation of GGA functionals (underestimated bandgaps) is expected to be considerably mitigated through the use of HSE06. ${ }^{30-38}$

To calculate the UV-Vis optical absorption properties of these materials, we applied DFPT, as implemented in VASP using the HSE06 formalism. The optical properties were obtained from the frequency-dependent complex dielectric function $\varepsilon(\omega)=\varepsilon_{1}(\omega)+i \varepsilon_{2}(\omega)$ following a methodology described in the literature. ${ }^{39}$ The real part $\varepsilon_{1}(\omega)$ was obtained using the Kramers-Kronig relation and it is defined as the electronic contribution to the dielectric constant, whereas the imaginary part $\varepsilon_{2}(\omega)$ was calculated by summing all possible transitions from occupied to unoccupied states in the Brillouin zone weighted with the matrix elements describing the probabilities of transition. To determine the fraction of the light absorbed in these materials, we calculated the optical absorption coefficient $\alpha(\omega)$ (in $\mathrm{cm}^{-1}$ ) for each compound as a function of the wavelength of the incident light using the following equations:

$$
\begin{gathered}
\alpha(\omega)=\frac{4 \pi k(\omega)}{\lambda} \\
k(\omega)=\left(\frac{\sqrt{\varepsilon_{1}^{2}+\varepsilon_{2}^{2}}-\varepsilon_{1}}{2}\right)^{\frac{1}{2}}
\end{gathered}
$$

where $\lambda$ and $\omega$ are the wavelength and frequency of the incident light, respectively, and $k(\omega)$ represents the extinction coefficient.

The vibrational contribution to the dielectric constant tensors $\left(\varepsilon_{\mathrm{vib}}\right)$ was obtained by computing the full phonon spectrum of the crystal using DFPT and the PBE functional in the framework of the linear response method implemented in VASP.

The effective mass tensors of photogenerated holes $\left(m_{\mathrm{h}}{ }^{*}\right)$ and electrons $\left(m_{\mathrm{e}}^{*}\right)$ at the band edges of these compounds were computed based on their $k$-space band structures obtained from the PBE functional using the following expression:

$$
\left(\frac{1}{m^{*}}\right)_{i j}=\frac{1}{2} \frac{\partial^{2} E_{n}(k)}{\partial k_{i} k_{j}} \quad(i, j=x, y, z)
$$

where $i$ and $j$ denote reciprocal components and $E_{n}(k)$ is the dispersion relation for the $n$-band. Note that the derivatives were evaluated numerically using the finite difference method. ${ }^{40}$

\section{Results and discussion}

\section{Structural properties}

We made an experimental attempt to synthesize single-phase pyrochlore bismuth titanate. We used the co-precipitation method to synthesize powder materials with various Ti/Bi precursor ratios. Samples with starting Ti/Bi molar ratios of 1 , $1.23,1.5,1.75$ and 2 were synthesized. The actual Ti/Bi ratios in these samples were confirmed via ICP and found to be 0.96 , 1.16, 1.51, 1.71 and 1.92, respectively. Fig. S1 shows the XRD patterns for the samples with varied $\mathrm{Ti} / \mathrm{Bi}$ molar ratios (ESI $\dagger$ ). Fig. S1 (ESI $\dagger$ ) shows a magnified view of the region in which amorphous phases appear $\left(23^{\circ}<2 \theta<28^{\circ}\right)$. It can be seen that 
for the sample with an initial $\mathrm{Ti} / \mathrm{Bi}$ ratio of 1 , a mixture of the pyrochlore phase with $\mathrm{Bi}_{4} \mathrm{Ti}_{3} \mathrm{O}_{12}$ as a secondary phase was obtained at $2 \theta=33^{\circ}$. The XRD pattern of the powder sample with a $\mathrm{Ti} / \mathrm{Bi}$ ratio of 1.16 showed a single phase of the pyrochlore structure with no impurities (neither a secondary nor an amorphous phase), and the peaks were indexed according to PDF\# 01-089-4732. The characteristic peaks of the pyrochlore structure were clearly observed for the (111) and (222) peaks. Indeed, no amorphous phase existed for the samples with $\mathrm{Ti} / \mathrm{Bi}$ ratios of 1.16 to 1.51 . Higher Ti/Bi ratios of 1.72 and 1.92 led to the formation of an amorphous phase that manifested as a broad increase in the background at $2 \theta$ values of 23 to $32^{\circ}$. This chemical composition was confirmed by an ICP measurement, in which a $\mathrm{Ti} / \mathrm{Bi}$ ratio of 1.16 was found, close to the initial ratio of 1.23. This confirmed that excess titanium created vacancies at the bismuth and oxygen sites, consistent with the proposal in the literature that such vacancies may stabilize the entire structure. ${ }^{17}$ It should be noted that the impurity phase

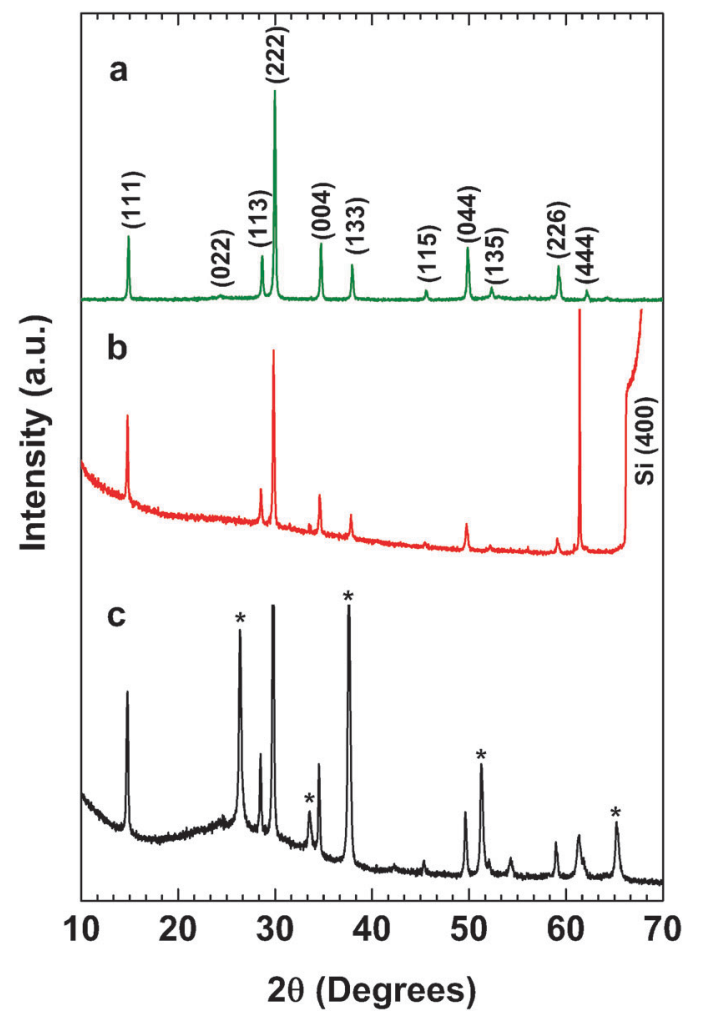

Fig. 2 XRD patterns of (a) $\mathrm{Bi}_{1.75} \mathrm{Ti}_{2} \mathrm{O}_{6.62}$ powders, (b) a $\mathrm{Bi}_{1.75} \mathrm{Ti}_{2} \mathrm{O}_{6.62}$ thin film on a Si substrate, and (c) a $\mathrm{Bi}_{1.75} \mathrm{Ti}_{2} \mathrm{O}_{6.62}$ thin film on an FTO substrate. * FTO. with low $\mathrm{Ti}\left(\mathrm{Bi}_{4} \mathrm{Ti}_{3} \mathrm{O}_{12}\right)$ caused the band edge to shift to longer wavelengths, whereas excess Ti would not cause any shift in the band edge, as observed from the Kubelka-Munk function from the UV-Vis spectroscopy results (Fig. S2, ESI $\dagger$ ). Further data and discussion on the stoichiometry of $\mathrm{Bi}_{2-x} \mathrm{Ti}_{2} \mathrm{O}_{7-1.5 x}$ can be found in ESI. $\dagger$

Therefore, for the subsequent characterizations presented in this work, we chose a ratio of $\mathrm{Ti} / \mathrm{Bi}=1.16$. Fig. 2 shows the representative XRD patterns for (a) the single-phase $\mathrm{Bi}_{2-x} \mathrm{Ti}_{2} \mathrm{O}_{7-1.5 x}$ powder synthesized using the co-precipitation method, to be refined using the Rietveld analysis method; (b) the $\mathrm{Bi}_{2-x} \mathrm{Ti}_{2} \mathrm{O}_{7-1.5 x}$ thin film deposited on a $\mathrm{Si}$ substrate, used for ellipsometric spectroscopy; and (c) the $\mathrm{Bi}_{2-x} \mathrm{Ti}_{2} \mathrm{O}_{7-1.5 x}$ thin film deposited on an FTO substrate, used for MottSchottky analysis. The thin film on the Si sample was calibrated versus the $\mathrm{Si}(400)$ peak, which appears at $2 \theta=69.12^{\circ}$. All of the samples exhibited a single-phase pyrochlore structure with the same $d$-spacing for the main peaks (e.g., $d_{222}=2.98 \AA$ ). The relative intensities of the peaks were similar to those in the powder samples, thereby confirming that the films were randomly oriented, similar to the polycrystalline powders.

Rietveld analysis was performed for the $\mathrm{Bi}_{2-x} \mathrm{Ti}_{2} \mathrm{O}_{7-1.5 x}$ sample with $\mathrm{Ti} / \mathrm{Bi}=1.16$ synthesized using the co-precipitation method. The Wyckoff positions of the atoms are summarized in Table S1 (ESI $\dagger$ ), and the lattice parameters are summarized in Table 1. The sample had a cubic structure belonging to the $F d 3 m$ space group and a lattice parameter of $a=10.35 \AA$. Bismuth ions $\left(\mathrm{Bi}^{3+}\right)$ partially occupied $96 \mathrm{~g}$, which is of lower symmetry than the normal atomic position (16c) in this space group. Titanium ions $\left(\mathrm{Ti}^{4+}\right)$ fully occupied the $16 \mathrm{~d}$ position, and two types of oxygen atoms were present, the first (O) fully occupying the 48f position and the second $\left(\mathrm{O}^{\prime}\right)$ partially occupying the $8 \mathrm{a}$ position. From Table S1 (ESI $\dagger$ ), the numbers of bismuth, titanium, and oxygen atoms deduced from their Wyckoff positions and the corresponding occupancies were 14, 16, and 53 atoms respectively. The chemical composition determined for this structure was $\mathrm{Bi}_{1.75} \mathrm{Ti}_{2} \mathrm{O}_{6.62}$.

We experimentally confirmed that the non-stoichiometric pyrochlore phase is prevalent in $\mathrm{Bi}_{2-x} \mathrm{Ti}_{2} \mathrm{O}_{7-1.5 x}$ with $x \sim 0.25$ (rich in Ti). Using the DFT/PBE computational method, we systematically investigated the crystal structure of the nonstoichiometric $\mathrm{Bi}_{1.75} \mathrm{Ti}_{2} \mathrm{O}_{6.62}$ structure and that of the ideal stoichiometric $\mathrm{Bi}_{2} \mathrm{Ti}_{2} \mathrm{O}_{7}$ structure for comparison. Fig. 1 shows the most relevant relaxed structures, and Table 1 reports their corresponding lattice parameters. For the non-stoichiometric compound, the structure with the lowest energy was obtained

Table 1 Lattice parameters measured via Rietveld refinement and calculated using the PBE functional for the various optimized structures shown in Fig. 2

\begin{tabular}{|c|c|c|c|c|c|c|}
\hline \multirow[b]{2}{*}{ Sample } & \multicolumn{6}{|c|}{ Lattice parameters $(\AA$, degree $)$} \\
\hline & $a$ & $b$ & $c$ & $\alpha$ & $\beta$ & $\gamma$ \\
\hline $\mathrm{Bi}_{1.75} \mathrm{Ti}_{2} \mathrm{O}_{6.62}$ (experimental) & 10.350 & 10.350 & 10.350 & 90.0 & 90.0 & 90 \\
\hline $\mathrm{Bi}_{1.75} \mathrm{Ti}_{2} \mathrm{O}_{6.62}$ (DFT; aggregated vacancies) & 10.290 & 10.404 & 10.322 & 91 & 90.2 & 90.4 \\
\hline $\mathrm{Bi}_{1.75} \mathrm{Ti}_{2} \mathrm{O}_{6.62}$ (DFT; separated vacancies) & 10.339 & 10.334 & 10.357 & 90.7 & 88.8 & 88.5 \\
\hline $\mathrm{Bi}_{2} \mathrm{Ti}_{2} \mathrm{O}_{7}(\mathrm{DFT})$ & 10.328 & 10.328 & 10.328 & 90 & 90 & 90 \\
\hline
\end{tabular}


for the configuration displaying a direct interaction between $2 \mathrm{Bi}$ and $3 \mathrm{O}$ vacancies (Fig. 1b). This interaction leads to the formation of a small cage in the lattice. Interestingly, upon relaxation, this structure retains very similar lattice parameters (lengths and angles) relative to the stoichiometric structure, in good agreement with the experimental data (Table 1). By contrast, another non-stoichiometric structure displaying well-separated $\mathrm{Bi}$ and $\mathrm{O}$ vacancies was found to be $0.2 \mathrm{eV}$ less stable than the previous one. In this case, the various atomic positions are strongly displaced upon relaxation from their initial positions, leading to different lattice parameters (especially the angles). The configuration with aggregated vacancies shows less cubic structure distortion $\left(\alpha, \beta, \gamma=91,90.2,90.4^{\circ}\right)$ in comparison with the configuration with well-separated vacancies $(\alpha, \beta, \gamma=$ $\left.90.7,88.8,88.5^{\circ}\right)$. Therefore, we chose to consider the structure with a small cage of defects for the following discussion of the computed material. The formation energy of the stoichiometric $\mathrm{Bi}_{2} \mathrm{Ti}_{2} \mathrm{O}_{7}$ was calculated to be $-1.608 \mathrm{eV}$ per $\mathrm{Bi}$ atom, whereas that of $\mathrm{Bi}_{1.75} \mathrm{Ti}_{2} \mathrm{O}_{6.62}$ was calculated to be $-1.783 \mathrm{eV}$ per $\mathrm{Bi}$ atom. This confirms that the non-stoichiometric structure is more stable, indicating that it is more favorable to obtain experimentally.

\section{Electronic structure and effective mass}

Fig. 3 shows the electronic density of states (DOS) computed for $\mathrm{Bi}_{1.75} \mathrm{Ti}_{2} \mathrm{O}_{6.62}$ using the HSE06 functional, compared with that for stoichiometric $\mathrm{Bi}_{2} \mathrm{Ti}_{2} \mathrm{O}_{7}$. The energy dispersion curves of these materials computed using the PBE functional are given in Fig. 4. The electronic analysis reveals that the valence-band states are governed by occupied $\mathrm{O} 2 \mathrm{p}$ orbitals with very weak contributions from Bi 6 s orbitals, whereas the conduction-band states are predominantly composed of $\mathrm{Ti} 3 \mathrm{~d}$ orbitals. Both

(a)

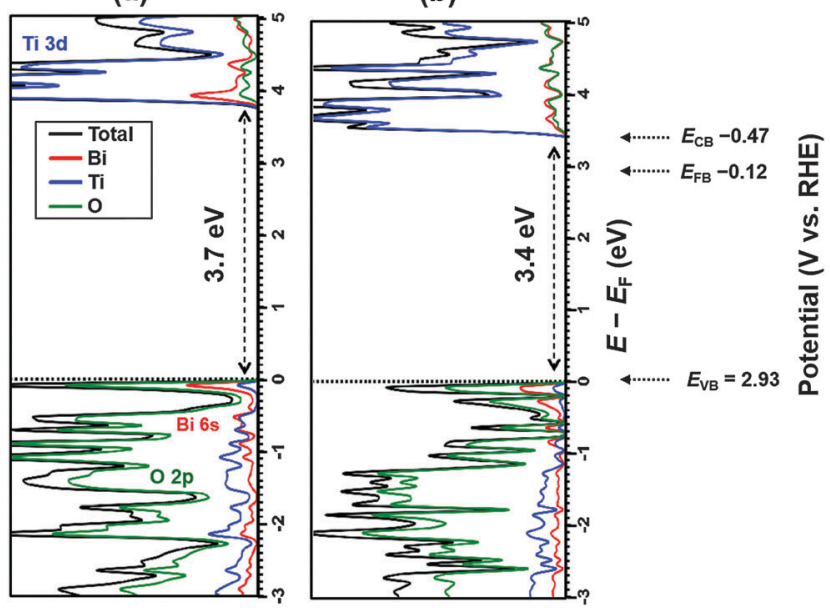

Fig. 3 Electronic DOSs obtained using the HSEO6 functional for (a) stoichiometric $\mathrm{Bi}_{2} \mathrm{Ti}_{2} \mathrm{O}_{7}$ and (b) non-stoichiometric $\mathrm{Bi}_{1.75} \mathrm{Ti}_{2} \mathrm{O}_{6.62}$ material in their most stable configurations, as reported in Fig. 2. Color legend: total DOS in black; DOSs projected onto $\mathrm{Bi}$ in red, onto $\mathrm{Ti}$ in blue, and onto $\mathrm{O}$ atoms in green. Potentials for valence band edge, conduction band edge, and flatband estimated from Mott-Schottky analysis are also represented on the RHE scale ( $\mathrm{pH}$ 13.2). (a)

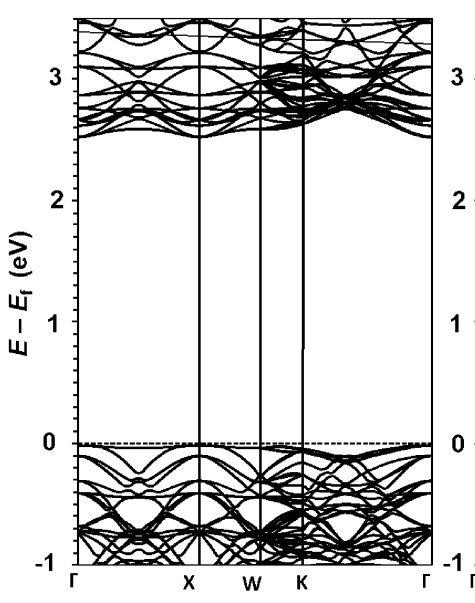

(b)

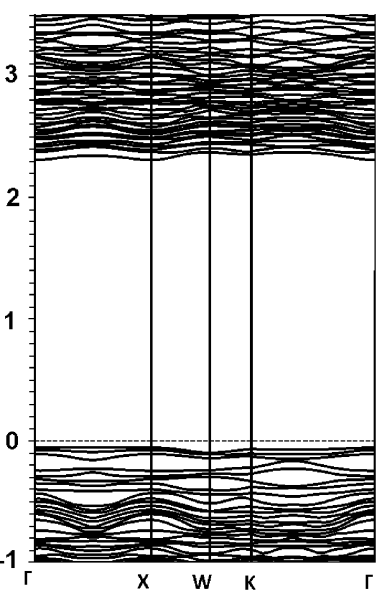

Fig. 4 Electronic band structure diagrams along the high-symmetry $k$-points obtained using the PBE functional for (a) stoichiometric $\mathrm{Bi}_{2} \mathrm{Ti}_{2} \mathrm{O}_{7}$ and (b) non-stoichiometric $\mathrm{Bi}_{1.75} \mathrm{Ti}_{2} \mathrm{O}_{6.62} ; E_{\mathrm{F}}$ is set at $\mathrm{O} \mathrm{eV}$.

compounds are direct (at the $\Gamma$ or $X$ point) semiconductors (Fig. 4), with bandgap energies of $3.7 \mathrm{eV}$ for $\mathrm{Bi}_{2} \mathrm{Ti}_{2} \mathrm{O}_{7}$ (Fig. 4a) and $3.4 \mathrm{eV}$ for $\mathrm{Bi}_{1.75} \mathrm{Ti}_{2} \mathrm{O}_{6.62}$ (Fig. $4 \mathrm{~b}$ ). The lowest-energy bandgaps of these materials originate primarily from $\mathrm{O} 2 \mathrm{p}^{6}-\mathrm{Ti} 3 \mathrm{~d}^{0}$ orbital transitions. By contrast, the DOSs calculated using the PBE functional yield much smaller bandgap energies of $2.5 \mathrm{eV}$ for $\mathrm{Bi}_{2} \mathrm{Ti}_{2} \mathrm{O}_{7}$ and $2.3 \mathrm{eV}$ for $\mathrm{Bi}_{1.75} \mathrm{Ti}_{2} \mathrm{O}_{6.62}$, consistent with previous theoretical studies of pyrochlore bismuth titanate. ${ }^{3,41}$ We also investigated the spin-orbit coupling effect on the electronic structures of $\mathrm{Bi}_{2} \mathrm{Ti}_{2} \mathrm{O}_{7}$ and $\mathrm{Bi}_{1.75} \mathrm{Ti}_{2} \mathrm{O}_{6.62}$ using the PBE functional, obtaining small decreases in the bandgaps of 0.1 and $0.2 \mathrm{eV}$, respectively. By comparing these relative shifts to the values obtained using the HSE06 functional, the bandgaps are predicted to be $3.6 \mathrm{eV}$ for $\mathrm{Bi}_{2} \mathrm{Ti}_{2} \mathrm{O}_{7}$ and $3.2 \mathrm{eV}$ for $\mathrm{Bi}_{1.75} \mathrm{Ti}_{2} \mathrm{O}_{6.62}$, in very good agreement with the measured values.

The effective mass tensors of photogenerated holes $\left(m_{\mathrm{h}}{ }^{*}\right)$ and electrons $\left(m_{\mathrm{e}}{ }^{*}\right)$ were computed at the band edges of $\mathrm{Bi}_{2} \mathrm{Ti}_{2} \mathrm{O}_{7}$ and $\mathrm{Bi}_{1.75} \mathrm{Ti}_{2} \mathrm{O}_{6.62}$ to evaluate their charge-carrier transport properties. Table 2 reports the values calculated in the three principal crystallographic directions. For $\mathrm{Bi}_{2} \mathrm{Ti}_{2} \mathrm{O}_{7}$, the effective electron and hole masses were found to be relatively small $(0.17,0.2$, and 0.87 for electrons and $0.56,0.75$, and 3.5 for holes in the [001], [010], and [100] directions, respectively). In the case of $\mathrm{Bi}_{1.75} \mathrm{Ti}_{2} \mathrm{O}_{6.62}$, the effective masses were found to be slightly higher both for electrons $(0.3,0.39$, and 1.66, respectively) and for holes $(0.45,36.4$, and 14 , respectively). In comparison, anatase $\mathrm{TiO}_{2}$ exhibits much lower effective electron and hole masses $\left(0.05 m_{0}\right.$ and $0.1 m_{0}$, respectively). ${ }^{18}$

Table 2 Calculated effective masses of electrons and holes in $\mathrm{Bi}_{1.75} \mathrm{Ti}_{2} \mathrm{O}_{6.62}$ and $\mathrm{Bi}_{2} \mathrm{Ti}_{2} \mathrm{O}_{7}$ in the principal crystallographic directions

\begin{tabular}{lllllll}
\hline & $m_{\mathrm{h}}{ }^{*}$ & \multicolumn{5}{c}{$m_{\mathrm{e}}{ }^{*}$} \\
\hline Direction & 100 & 010 & 001 & 100 & 010 & 001 \\
$\mathrm{Bi}_{1.75} \mathrm{Ti}_{2} \mathrm{O}_{6.62}$ & 14 & 36 & 0.45 & 1.7 & 0.39 & 0.30 \\
$\mathrm{Bi}_{2} \mathrm{Ti}_{2} \mathrm{O}_{7}$ & 3.5 & 0.75 & 0.56 & 0.87 & 0.20 & 0.17
\end{tabular}


This reflects the excellent transport properties in the $\mathrm{TiO}_{2}$ system.

\section{Dielectric properties}

The dielectric constant $\left(\varepsilon_{\mathrm{r}}\right)$ is a frequency-dependent parameter and consists of two components: an ionic vibrational polarization component $\left(\varepsilon_{\mathrm{vib}}\right)$ and an electronic polarization component $\left(\varepsilon_{\infty}\right)$. At high frequencies relevant to the UV-Vis region considered in our experimental study $\left(10^{14}-10^{15} \mathrm{~Hz}\right)$, the dielectric constant deduced via spectroscopic ellipsometry contains only the electronic contribution. At lower frequencies $\left(<10^{13} \mathrm{~Hz}\right)$, the vibrational contribution dominates, which is relevant for Mott-Schottky analysis, as previously discussed.

Through retro-simulation of the experimental data, we can deduce the film thickness and also extract the refractive index $(n)$ and the absorption index ( $k$ ) (Fig. S3, ESI $\dagger$ ). To correlate the complex refractive index with the dielectric properties, the following equation is applied:

$$
\varepsilon=\varepsilon_{1}+i \varepsilon_{2}=N^{2}=(n+i k)^{2}
$$

Thus, we can deduce the dielectric constant as follows:

$$
\varepsilon_{1}=\varepsilon_{\infty}=n^{2}-k^{2} .
$$

Concerning the electronic contribution to the dielectric constant $\left(\varepsilon_{\infty}\right)$, Fig. 5 displays the results measured via ellipsometry and calculated using the DFPT/HSE06 method through the real part $\varepsilon_{1}(\omega)$ of the frequency dependent dielectric function (see Computational methods for more details). Experimentally, we found $\varepsilon_{\infty}$ to be equal to 9.8 at a bandgap of $3.3 \mathrm{eV}$. From the calculations, dielectric constants of 8.8 and 6.5 were obtained for the stoichiometric $\mathrm{Bi}_{2} \mathrm{Ti}_{2} \mathrm{O}_{7}$ compound and the non-stoichiometric $\mathrm{Bi}_{1.75} \mathrm{Ti}_{2} \mathrm{O}_{6.62}$ compound, respectively. Moreover, both structures were found to be isotropic materials along the $x x, y y$ and $z z$ directions. This means that the light absorption and the subsequent exciton dissociation do not depend on the direction $(x, y$ or $z)$ of polarization of the light. In comparison with $\mathrm{TiO}_{2}$ $\left(\varepsilon_{\infty}=6\right)$, the bismuth titanate structure possesses a higher dielectric constant. ${ }^{18}$

The ionic contributions $\varepsilon_{\text {vib }}$ were calculated using the DFPT/ $\mathrm{PBE}$ approach. We obtained a value of 80.1 for the stoichiometric $\mathrm{Bi}_{2} \mathrm{Ti}_{2} \mathrm{O}_{7}$ compound in all three crystallographic directions. However, for the non-stoichiometric $\mathrm{Bi}_{1.75} \mathrm{Ti}_{2} \mathrm{O}_{6.62}$ structure, the ionic contributions were 56.6, 76.8 and 87.4 in the $x x, y y$ and $z z$ directions, respectively. Higher dielectric constants were previously reported for these materials (101 and 104), ${ }^{42,43}$ but those observed here still surpass the dielectric constant value of 45.7 for $\mathrm{TiO}_{2}{ }^{44}$

\section{Absorption properties}

In Fig. 6, the measured and calculated absorption coefficients of non-stoichiometric $\mathrm{Bi}_{1.75} \mathrm{Ti}_{2} \mathrm{O}_{6.62}$ are plotted, together with the corresponding results calculated for stoichiometric $\mathrm{Bi}_{2} \mathrm{Ti}_{2} \mathrm{O}_{7}$. The experimental value of the absorption coefficient was deduced from the imaginary part of the dielectric constant measured via spectroscopic ellipsometry. We investigated the bandgap of the non-stoichiometric $\mathrm{Bi}_{1.75} \mathrm{Ti}_{2} \mathrm{O}_{6.62}$ structure using spectroscopic
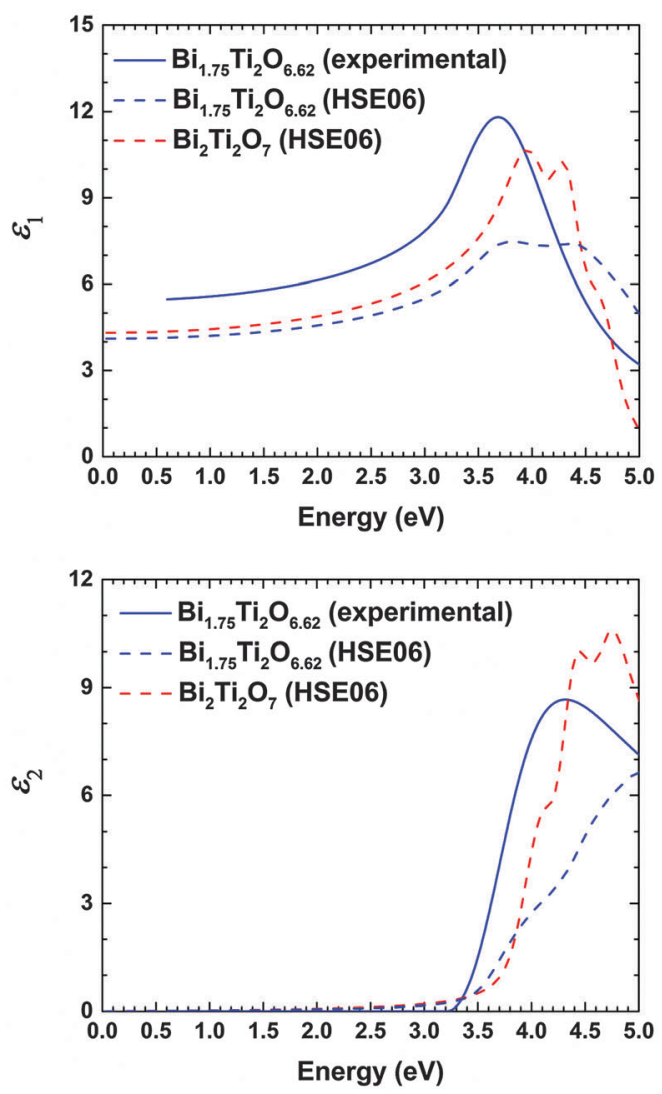

Fig. 5 The dielectric function for the $\mathrm{Bi}_{1.75} \mathrm{Ti}_{2} \mathrm{O}_{6.62}$ structure measured via spectroscopic ellipsometry (solid blue line) and those calculated using the HSE06 functional for the same non-stoichiometric structure (dashed blue line) and for the stoichiometric $\mathrm{Bi}_{2} \mathrm{Ti}_{2} \mathrm{O}_{7}$ compound (dashed red line).

ellipsometry. The inset of Fig. 6 shows the Tauc plot for the direct transition, ${ }^{45}$ indicating a bandgap of approximately $3.3 \mathrm{eV}$. The bandgap values previously reported in the literature are much smaller: theoretically, they have been reported to be $2.6^{3}$ and $2.89 \mathrm{eV},{ }^{41}$ and experimentally, they have been found to be $2.9,{ }^{46} 2.95,{ }^{5}$ and $3.0 \mathrm{eV} .^{6}$ These lower previously reported bandgaps can be explained by the presence of secondary phases (e.g., $\mathrm{Bi}_{4} \mathrm{Ti}_{3} \mathrm{O}_{12}$ ) with smaller bandgaps. A reduced bandgap was indeed observed for the sample that contained a $\mathrm{Bi}_{4} \mathrm{Ti}_{3} \mathrm{O}_{12}$ phase $(\sim 2.95 \mathrm{eV})$ with a $\mathrm{Ti} / \mathrm{Bi}$ ratio of 1 , as shown in Fig. S2 (ESI $\dagger)$. It has been reported that as the fraction of the $\mathrm{Bi}_{4} \mathrm{Ti}_{3} \mathrm{O}_{12}$ phase in the sample increases, the color of the powder changes from pale white to yellow. ${ }^{14}$ Hence, accurate measurements of the bandgap can only be achieved using the single-phase material. From Fig. 6, it can be seen that the calculated absorption coefficient for $\mathrm{Bi}_{1.75} \mathrm{Ti}_{2} \mathrm{O}_{6.62}$ (dashed blue line) agrees well with the measured one. Both show an onset of absorbance at approximately $3.3 \mathrm{eV}$, consistent with the observed bandgap energy. It can be seen that the non-stoichiometric structure exhibits a narrowing of the bandgap with respect to the stoichiometric $\mathrm{Bi}_{2} \mathrm{Ti}_{2} \mathrm{O}_{7}$ structure. This confirms that an accurate description of the absorption properties of the pyrochlore bismuth titanate structure is achievable by considering non-stoichiometric effects, i.e., the presence of $(\mathrm{Bi}, \mathrm{O})$ vacancies in the structure. 


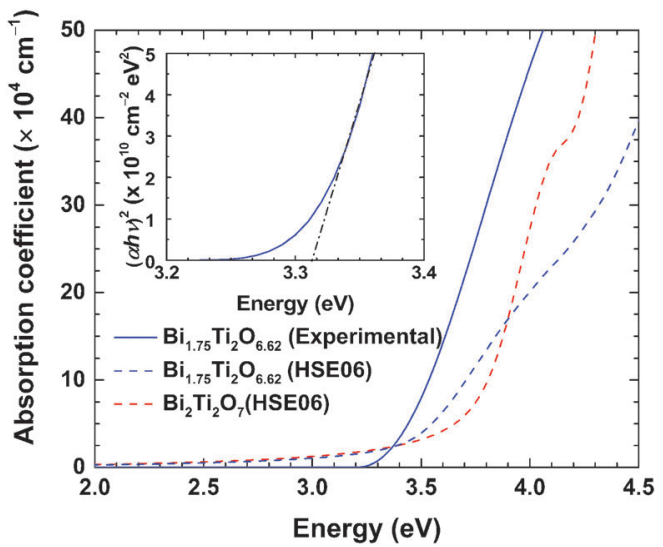

Fig. 6 Absorption coefficients of the spectra of $\mathrm{Bi}_{1.75} \mathrm{Ti}_{2} \mathrm{O}_{6.62}$ obtained via ellipsometric spectroscopy (solid blue line) and computed using the HSEO6 functional, together with the results computed for $\mathrm{Bi}_{2} \mathrm{Ti}_{2} \mathrm{O}_{7}$. The inset shows the Tauc plot of the measured results for $\mathrm{Bi}_{1.75} \mathrm{Ti}_{2} \mathrm{O}_{6.62}$.

\section{Band positions}

We performed Mott-Schottky measurements of the $\mathrm{Bi}_{1.75} \mathrm{Ti}_{2} \mathrm{O}_{6.62}$ film on the FTO substrate. A frequency range of 70 to $150 \mathrm{~Hz}$ was chosen by analyzing the Bode plot (Fig. S4a, ESI $\dagger$ ), and the potential range $(0.6-1.0 \mathrm{~V} v s$. RHE) was chosen to be the double-layer region in which there is no faradic current (Fig. S4b, ESI $\dagger$ ). Fig. 7 shows the Mott-Schottky plot for the $\mathrm{Bi}_{1.75} \mathrm{Ti}_{2} \mathrm{O}_{6.62}$ film.

We can see from the positive slope that the $\mathrm{Bi}_{1.75} \mathrm{Ti}_{2} \mathrm{O}_{6.62}$ material has an n-type nature. According to the Mott-Schottky equation,

$$
\frac{1}{C^{2}}=\frac{2}{\varepsilon_{0} \varepsilon_{\mathrm{r}} e N_{\mathrm{D}} A^{2}}\left(E-E_{\mathrm{FB}}-\frac{k_{\mathrm{B}} T}{e}\right)
$$

where $C$ is the capacitance, $\varepsilon_{0}$ is the vacuum permittivity, $\varepsilon_{\mathrm{r}}$ is the dielectric constant, $N_{\mathrm{D}}$ is the majority carrier concentration, $A$ is the electrode area, $k_{\mathrm{B}}$ is the Boltzmann constant, $T$ is the temperature, and $e$ is the elementary charge. The value of the dielectric constant $\varepsilon_{\mathrm{r}}$ (73.6) was obtained from theoretical calculations of both the ionic and electronic vibrational contributions because the Mott-Schottky measurement was

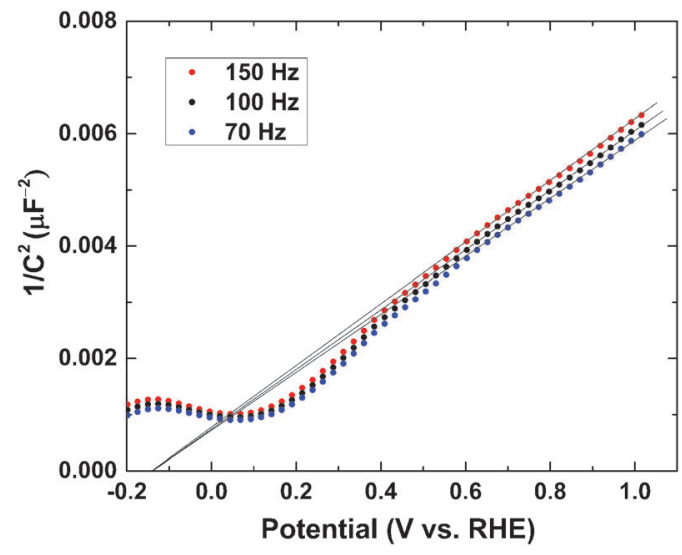

Fig. 7 Mott-Schottky plot for non-stoichiometric $\mathrm{Bi}_{1.75} \mathrm{Ti}_{2} \mathrm{O}_{6.62}$.
Table 3 Summary of semiconductor properties deduced through MottSchottky analysis

\begin{tabular}{ll}
\hline Parameter & Value \\
\hline$\varepsilon_{\infty}$ & 9.8 \\
$\varepsilon_{\text {vib(DFPT/PBE) }}$ & 73.6 \\
$N_{\mathrm{D}}$ & $3.26 \times 10^{18} \mathrm{~cm}^{-3}$ \\
$N_{\mathrm{C}}$ & $4.12 \times 10^{18} \mathrm{~cm}^{-3}$ \\
$m_{\mathrm{e}}{ }^{*}$ & 0.3 \\
$E_{\mathrm{C}}$ & $-0.47 \mathrm{~V} v s . \mathrm{RHE}$ \\
$E_{\mathrm{FB}}$ & $-0.12 \mathrm{~V} v s . \mathrm{RHE}$ \\
\end{tabular}

performed at relatively low frequencies and therefore included the ionic vibrational contribution. The flatband potential $E_{\mathrm{FB}}$ was deduced from the intercept of the plot as a function of the applied potential $E$, yielding an $E_{\mathrm{FB}}$ of $-0.12 \mathrm{~V} v s$. RHE.

The majority carrier concentration $\left(N_{\mathrm{D}}\right)$ was found to be $3.26 \times 10^{18} \mathrm{~cm}^{-3}$ from the slope of the plot. Next, the density of states in the conduction band $\left(N_{\mathrm{C}}\right)$ was calculated using eqn (7):

$$
N_{\mathrm{C}}=\left(\frac{2}{h^{3}}\right)\left(2 \pi m_{\mathrm{e}}{ }^{*} k T\right)^{\frac{3}{2}}
$$

where $h$ is Planck's constant and $m_{\mathrm{e}}{ }^{*}$ is the effective electron mass. From this measurement, the electron effective mass was found to be $0.3 m_{0}$.

We could also deduce the difference between the bottom of the conduction band $\left(E_{\mathrm{C}}\right)$ and $E_{\mathrm{FB}}$ using eqn (8):

$$
E_{\mathrm{C}}-E_{\mathrm{FB}}=-k T \ln \left(\frac{N_{\mathrm{D}}}{N_{\mathrm{C}}}\right)
$$

The edge of the conduction band was measured to lie at $-0.47 \mathrm{~V}$ vs. RHE. Consequently, $\mathrm{Bi}_{1.75} \mathrm{Ti}_{2} \mathrm{O}_{6.62}$ has a more negative conduction band edge than does $\mathrm{TiO}_{2}$, whose conduction band edge has been reported to lie at $-0.19 \mathrm{~V} v s$. RHE under similar pH conditions. ${ }^{47}$ The result is added into Fig. 3 on the RHE scale ( $\mathrm{pH}$ 13.2). This more negatively located conduction band may allow this material to be applied as an alternative anode material in place of $\mathrm{TiO}_{2}$ in dye-sensitized solar cells to increase the open-circuit potential. The parameters obtained through Mott-Schottky analysis are summarized in Table 3.

To summarize the comparison with the well-studied material $\mathrm{TiO}_{2}$, higher dielectric constants and higher effective masses were observed in the pyrochlore $\mathrm{Bi}_{1.75} \mathrm{Ti}_{2} \mathrm{O}_{6.62}$ system. The most prominent difference was evident in the flatband potentials; $\mathrm{Bi}_{1.75} \mathrm{Ti}_{2} \mathrm{O}_{6.62}$ possesses a more negatively located conduction band, although the bandgap and absorption properties are similar. To take full advantage of these properties, a $\mathrm{Bi}_{1.75} \mathrm{Ti}_{2} \mathrm{O}_{6.62} / \mathrm{TiO}_{2}$ composite may result in better overall performance than either $\mathrm{TiO}_{2}$ or $\mathrm{Bi}_{2} \mathrm{Ti}_{2} \mathrm{O}_{7}$ alone for photocatalytic reactions. ${ }^{48}$

\section{Conclusions}

A study combining experimental and theoretical methods was conducted to investigate the optoelectronic properties of the nonstoichiometric $\mathrm{Bi}_{2-x} \mathrm{Ti}_{2} \mathrm{O}_{7-1.5 x}$ structure $(x=0.25)$, in which a clear distinction between this material and the ideal perfect 
stoichiometric configuration $(x=0)$ was observed. Our calculated results for the bandgap and absorption coefficient of the nonstoichiometric structure $\left(\mathrm{Bi}_{1.75} \mathrm{Ti}_{2} \mathrm{O}_{6.62}\right)$ exhibited excellent agreement with the bandgap of $3.3 \mathrm{eV}$ measured via ellipsometry, which is narrower than the bandgap computed for the stoichiometric $\mathrm{Bi}_{2} \mathrm{Ti}_{2} \mathrm{O}_{7}$ material $(3.6 \mathrm{eV})$. The nature of the bandgap was found to be direct as a result of a transition at the $\Gamma$ or $X$ point. Our calculated static dielectric constants exhibited high values of up to 80.1 for $\mathrm{Bi}_{1.75} \mathrm{Ti}_{2} \mathrm{O}_{6.62}$. The results indicate that the material is highly anisotropic, with high effective electron and hole masses in certain directions, which may result in lower charge-carrier mobility. The flatband potential and the bottom of the conduction band were measured in $0.1 \mathrm{M} \mathrm{NaOH}$ solution ( $\mathrm{pH}$ 13.2) to be -0.12 and $-0.47 \mathrm{~V}$ vs. RHE, respectively, more negative than those of the well-known $\mathrm{TiO}_{2}$ compound. This study identified several key parameters of the pyrochlore $\mathrm{Bi}_{2-x} \mathrm{Ti}_{2} \mathrm{O}_{7-1.5 x}$ material, which may have various potential applications, e.g., may be substituted for or mixed with $\mathrm{TiO}_{2}$ in dye-sensitized solar cells and photocatalytic applications.

\section{Acknowledgements}

The research reported in this work was supported by the King Abdullah University of Science and Technology.

\section{Notes and references}

1 B. O'Regan and M. Gratzel, Nature, 1991, 353, 737.

2 A. Fujishima and K. Honda, Nature, 1972, 238, 37.

3 S. Murugesan, M. N. Huda, Y. Yan, M. M. Al-Jassim and V. Subramanian, J. Phys. Chem. C, 2010, 114, 10598.

4 M. T. Weller, R. W. Hughes, J. Rooke, C. S. Knee and J. Reading, Dalton Trans., 2004, 3032.

5 W. F. Yao, H. Wang, X. H. Xu, J. T. Zhou, X. N. Yang, Y. Zhang and S. X. Shang, Appl. Catal., A, 2004, 259, 29.

6 O. Merka, D. W. Bahnemann and M. Wark, Catal. Today, 2014, 225, 102.

7 H. Zhou, T.-J. Park and S. S. Wong, J. Mater. Res., 2006, 21, 2941.

8 Z. Bian, Y. Huo, Y. Zhang, J. Zhu, Y. Lu and H. Li, Appl. Catal., B, 2009, 91, 247.

9 J. Hou, S. Jiao, H. Zhu and R. V. Kumar, J. Solid State Chem., 2011, 184, 154.

10 X. H. Xu, W. F. Yao, Y. Zhang, A. Q. Zhou, Y. Hou and M. Wang, Acta Chim. Sin., 2005, 63, 5.

11 Y. Hou, M. Wang, X.-H. Xu, D. Wang, H. Wang and S.-X. Shang, J. Am. Ceram. Soc., 2002, 85, 3087.

12 W.-F. Su and Y.-T. Lu, Mater. Chem. Phys., 2003, 80, 632.

13 A. L. Hector and S. B. Wiggin, J. Solid State Chem., 2004, 177, 139.

14 J. R. Esquivel-Elizondo, B. B. Hinojosa and J. C. Nino, Chem. Mater., 2011, 23, 4965.

15 O. Knop, F. Brisse and L. Castelliz, Can. J. Chem., 1969, 47, 971.

16 V. Kahlenberg and H. Bohm, Acta Crystallogr., Sect. B: Struct. Sci., 1995, 51, 11.
17 I. Radosavljevic, J. S. O. Evans and A. W. Sleight, J. Solid State Chem., 1998, 136, 63.

18 T. Le Bahers, M. Rérat and P. Sautet, J. Phys. Chem. C, 2014, 118, 5997.

19 M. Harb, Phys. Chem. Chem. Phys., 2015, 17, 25244.

20 G. Kresse and J. Hafner, Phys. Rev. B: Condens. Matter Mater. Phys., 1994, 49, 14251.

21 G. Kresse and J. Furthmüller, Comput. Mater. Sci., 1996, 6, 15.

22 G. Kresse and J. Furthmüller, Phys. Rev. B: Condens. Matter Mater. Phys., 1996, 54, 11169.

23 G. Kresse and D. Joubert, Phys. Rev. B: Condens. Matter Mater. Phys., 1999, 59, 1758.

24 J. P. Perdew, K. Burke and M. Ernzerhof, Phys. Rev. Lett., 1996, 77, 3865.

25 P. E. Blöchl, Phys. Rev. B: Condens. Matter Mater. Phys., 1994, 50, 17953.

26 H. J. Monkhorst and J. D. Pack, Phys. Rev. B: Condens. Matter Mater. Phys., 1976, 13, 5188.

27 J. Heyd, G. E. Scuseria and M. Ernzerhof, J. Chem. Phys., 2003, 118, 8207.

28 J. Heyd, G. E. Scuseria and M. Ernzerhof, J. Chem. Phys., 2006, 124, 219906.

29 J. Paier, M. Marsman, K. Hummer, G. Kresse, I. C. Gerber and J. G. Ángyán, J. Chem. Phys., 2006, 125, 249901.

30 M. Harb, L. Cavallo and J. M. Basset, J. Phys. Chem. C, 2014, 118, 20784.

31 M. Harb, P. Sautet, E. Nurlaela, P. Raybaud, L. Cavallo, K. Domen, J. M. Basset and K. Takanabe, Phys. Chem. Chem. Phys., 2014, 16, 20548.

32 M. Harb, P. Sautet and P. Raybaud, J. Phys. Chem. C, 2013, 117, 8892.

33 M. Harb, D. Masih, S. Ould-Chikh, P. Sautet, J.-M. Basset and K. Takanabe, J. Phys. Chem. C, 2013, 117, 17477.

34 M. Harb, J. Phys. Chem. C, 2015, 119, 4565.

35 M. Harb, J. Phys. Chem. C, 2013, 117, 25229.

36 M. Harb, P. Sautet and P. Raybaud, J. Phys. Chem. C, 2011, 115, 19394.

37 M. Harb, D. Masih and K. Takanabe, Phys. Chem. Chem. Phys., 2014, 16, 18198.

38 M. Harb, J. Phys. Chem. C, 2013, 117, 12942.

39 M. Gajdoš, K. Hummer, G. Kresse, J. Furthmüller and F. Bechstedt, Phys. Rev. B: Condens. Matter Mater. Phys., 2006, 73, 045112.

40 A. Fonari and C. Sutton, http://afonari.com/emc/.

41 W. Wei, Y. Dai and B. Huang, J. Phys. Chem. C, 2009, 113, 5658.

42 W. F. Su and Y. T. Lu, Mater. Chem. Phys., 2003, 80, 632.

43 Y. Hou, M. Wang, X. H. Xu, D. Wang, H. Wang and S. X. Shang, J. Am. Ceram. Soc., 2002, 85, 3087.

44 R. J. Gonzalez, R. Zallen and H. Berger, Phys. Rev. B: Condens. Matter Mater. Phys., 1997, 55, 7014.

45 R. G. J. Tauc and A. Vancu, Phys. Status Solidi, 1966, 15, 627. 46 A. Kudo and S. Hijii, Chem. Lett., 1999, 1103.

47 S. Burnside, J.-E. Moser, K. Brooks, M. Grätzel and D. Cahen, J. Phys. Chem. B, 1999, 103, 9328.

48 H. Liu, Y. Chen, G. Tian, Z. Ren, C. Tian and H. Fu, Langmuir, 2015, 31, 5962. 